\title{
誘導体化/電子プローブ $\mathrm{X}$ 線マイクロアナリシスによる 高分子材料中のカルボニル基の分布分析*
}

\author{
杉浦 元保 ${ }^{\circledR * *} \cdot$ 辻 正 男 $^{* *} \cdot$ 村 瀬 篤 ${ }^{* *} \cdot$ 光岡 拓哉 ${ }^{* *}$
}

Distribution analysis of carbonyl groups in a polymer by derivatization/electron probe X-ray micro-analysis

Motoyasu Sugiura, Masao Tsuji, Atsushi Murase and Takuya Mitsuoka ${ }^{* *}$

${ }^{* *}$ Toyota Central R\&D Labs. Inc., 41 - 1, Nagakute, Nagakute-cho, Aichi 480 - 1192

(Received 9 June 1999, Accepted 11 August 1999)

\begin{abstract}
An analytic method, referred to as "derivatization/electron probe X-ray micro-analysis (EPMA)", has been developed to determine the distribution of a small amount of carbonyl groups formed by the oxidation of polymers by chemical derivatization with 2,4,6trichlorophenylhydrazine (TCPH). A suitable condition of the derivatization reaction with carbonyl groups in polymers was investigated. It was found that the highest reaction yield and selectivity were obtained by heating the sample in a $2.5 \% \mathrm{TCPH} /$ acetic acid solution at $90^{\circ} \mathrm{C}$ for $30 \mathrm{~min}$. Acetic acid was used as a catalyst and a solvent. By derivatization/EPMA using this reaction condition, a distribution measurement of the carbonyl group in the polymer became possible in $0.01 \%$ of the detection limits. Actual applications to a depth analysis of degraded ethylene-carbon mono oxide copolymer and polyethylene proved that this method is useful for the characterization of polymers and studies on polymer degradation.
\end{abstract}

Keywords : distribution analysis; chemical derivatization; electron probe X-ray microanalysis; polyolefin; carbonyl group.

\section{1 緒言}

高分子材料は熱, 光などの環境因子の作用により化学 変化（劣化）を起こし, 多くの場合初期性能を失う。こ のため, 使用に当たっては材料の劣化機構を解析し, 使 用環境に適した試験法により正しく評価することが必要 となる．そのためには物性的な評価に加えて化学的な評

* 誘導体化/EPMA 法の開発（第 3 報）。前報は村瀬 篤, 光岡拓哉, 杉浦元保, 荒賀年美: 分析化学, 46, 37 (1997).

**（株）豊田中央研究所：480-1192 愛知県愛知郡長久手 町長湫字横道 41-1
価が必要となる.一方, 材料の環境因子による劣化は, 表面から内部に向かって進行する場合が多いと考えられ るため, 劣化によって生じた組成や官能基量の変化を, 材料の表面又は表面から内部へと調べることが重要とな っている.

そこで著者らは, 高分子材料中に存在する, あるいは 劣化により生成する微量官能基の分布を, $\mu \mathrm{m}$ オーダー の位置分解能で分析する方法として, 誘導体化/電子プ ローブ X 線マイクロアナリシス (“誘導体化/EPMA 法”)

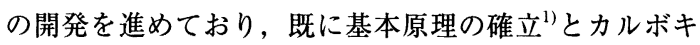
シル基の誘導体化条件の最適化を行った ${ }^{2)}$. 
Table 1 Derivatization reaction of carbonyl groups in polymers

\begin{tabular}{ccc}
\hline Reagent & Indicator element & Ref. \\
\hline $\begin{array}{c}\text { Pentafluorophenyl hydrazine } \\
\left(\mathrm{NH}_{2} \mathrm{NHC}_{6} \mathrm{~F}_{5}\right)\end{array}$ & $\mathrm{F}, \mathrm{N}$ & $3)$ \\
$\begin{array}{c}\text { 2,4-Dinitrophenyl hydrazine } \\
\left(\mathrm{NH}_{2} \mathrm{NHC}_{6} \mathrm{H}_{3}\left(\mathrm{NO}_{2}\right)_{2}\right)\end{array}$ & $\mathrm{N}$ & $4)$ \\
$\begin{array}{c}\mathrm{Hydrazine} \\
\left(\mathrm{NH}_{2} \mathrm{NH}_{2}\right)\end{array}$ & $\mathrm{N}$ & $5)$ \\
$\begin{array}{c}\text { Chlorophenyl hydrazine } \\
\left(\mathrm{NH}_{2} \mathrm{NHC}_{6} \mathrm{H}_{5} \mathrm{Cl}\right)\end{array}$ & $\mathrm{Cl}$ & $6)$ \\
\hline
\end{tabular}

本研究では，ポリオレフィンなどの高分子材料の酸化 劣化において重要な生成物であるカルボニル基につい て, 新しい誘導体化試薬として 2,4,6-トリクロロフェニ ルヒドラジン（TCPH）を用いた誘導体化の最適条件を 検討した。 また，本法を劣化させた高分子材料中のカル ボニル基の深さ方向分析に適用し，ポリエチレンなどの ポリオレフィンの酸化劣化状態の解析に有効であること を確認した．既報で検討したカルボキシル基は酸化劣化 で生成する以外に，ポリエステルやポリアミドなどでは 加水分解でも生成するものであるのに対して，本報で検 討したカルボニル基は酸化劣化でのみ生成するものであ り, 劣化機構を解析したり, 劣化度を評価する場合の重 要な官能基の一つである.

\section{2 カルボニル基の誘導体化反応}

高分子材料中のカルボニル基の誘導体化反応は, $\mathrm{X}$ 線 光電子分光法（XPS）におけるラベル化を目的として 種々検討されている ${ }^{3) \sim 6)}$. これまでに知られている誘導 体化反応の代表例を Table 1 に示す. また, カルボニ ル基の誘導体化としては, このほかにオキシム化法や酸 性亜硫酸ナトリウム法などが知られているが, いずれも 水系であったり, EPMAに高感度な元素を含まなかった りする. Table 1のクロロフェニルヒドラジンが, 本法 に適する唯一の誘導体化試薬である. 本研究では更に高 感度が期待できる， Cl 元素を 3 個有した 2,4,6-トリクロ ロフェニルヒドラジン（TCPH）を新しい誘導体化試薬 として, 誘導体化/EPMA 法に必要な条件 ${ }^{2}$ を満たす最 適な反応条件を検討することとした.

\section{3 実験}

\section{1 試料・試薬}

1）検討用試料：カルボニル基を構造内に持つ高分子 として, エチレンー一酸化炭素共重合体（E-CO ポリマ
一, 日本ユニカー製, 厚さ: $50 \mu \mathrm{m}$, カルボニル基濃度: $1 \% ， 3 \%$ を用いた.

また，カルボニル基を持たず，カルボニル基以外の官 能基を持つ高分子としてポリアクリル酸（PAA，住友化 学製), ポリブチレンテレフタレート（PBT, 東レ製), ナイロン-6 (Ny-6，東レ製)，エチレンービニルアルコー ル共重合体（PE-PVA，クラレ製）の板又はフィルムを 用いた。

2）反応試薬：誘導体化試薬として TCPH (Aldrich 製, 特級), 溶媒としてエ夕ノール, 触媒として酢酸, 硫酸, 硝酸及びリン酸（いずれも和光純薬製，特級）を用い た.

\section{$3 \cdot 2$ 誘導体化}

誘導体化は，試料を入れた共栓付きの三角フラスコに TCPH のエタノール溶液と触媒を加えた誘導体化試薬を 入れ，加温することにより行った，但し，最終的にはエ 夕ノールは不要であることが分かったため, 溶媒と触媒 とを兼ねた $100 \%$ 酰酸に TCPH を溶解した誘導体化試 薬を用いることとした，反応後には，試料中に残存する 未反応試薬を $100 \%$ 酢酸に浸せきすることにより除去し た.また，試料中に浸透する酢酸は真空乾燥（一昼夜） により除去した.

\section{$3 \cdot 3$ 測定条件}

1）EPMAによる線分析：EPMA は島津製 EPM-810Q 型を用い，測定はビーム径が $1 \mu \mathrm{m}$ ，加速電圧が $20 \mathrm{kV}$, 試料電流が $20 \mathrm{nA}$, 走查速度が $50 \mu \mathrm{m} / \mathrm{min}$ の線分析モ ードで行った. 定量は検出 $\mathrm{X}$ 線に $\mathrm{Cl}$ の $\mathrm{K} \alpha(0.4728 \mathrm{~nm})$ 線を用い, $\mathrm{KCl}$ を標準物質として $\mathrm{ZAF}$ 補正により行っ た。但し，誘導体化の最適条件の決定はビーム径 100 $\mu \mathrm{m}$ の点分析モードによって行った.

2）顕微 IRによる線分析：顕微 IR は日本電子製 MAU110 顕微赤外ユニット付き JIR-100 型フーリエ变換 赤外分光計を用い, 測定はスリットが幅 $20 \mu \mathrm{m} \times$ 長さ $50 \mu \mathrm{m}$, 送り幅が $20 \mu \mathrm{m}$ の線分析モードで行った.

\section{4 結 果}

\section{$4 \cdot 1$ 誘導体化試薬の組成}

4・1・1 触媒とその濃度触媒はヒドラジンの反応 で一般的に用いられる鉱酸又は有機酸から硫酸，硝酸， リン酸及び酢酸を選び，触媒の種類，濃度と反応後の EPMA 測定による $\mathrm{Cl}$ 濃度（反応率）との関係を調べた. 溶媒は試料の損傷がないエ夕ノールを用い, TCPH 濃度 は $2.5 \mathrm{wt} \%$, 反応温度は $90^{\circ} \mathrm{C}$, 反応時間は 30 分とした. 


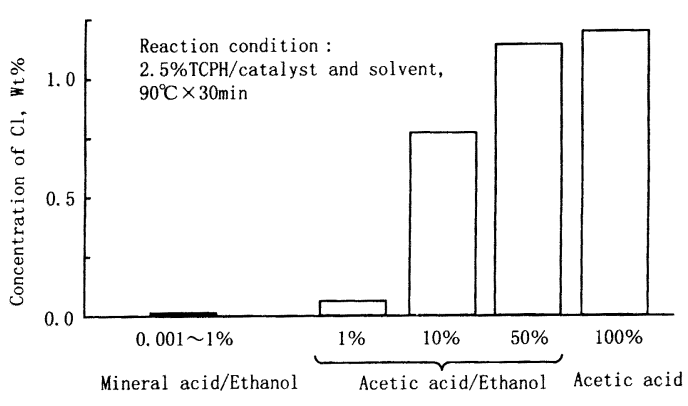

Fig. 1 Relation between the concentration of a catalyst and the concentration of $\mathrm{Cl}$ obtained by EPMA after reaction

Mineral acid: sulfuric acid, nitric acid, phosphoric acid

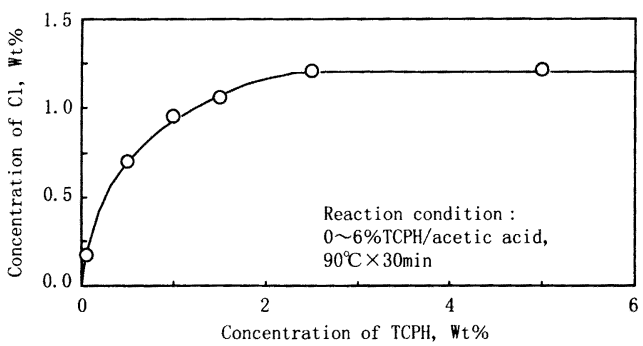

Fig. 2 Relation between the concentration of $\mathrm{TCPH}$ as a reaction reagent and the concentration of $\mathrm{Cl}$ obtained by EPMA after reaction

その結果を Fig. 1 に示す. 横軸に触媒の種類と濃度を 表し, 縦軸に反応後の EPMA 測定による $\mathrm{Cl}$ 濃度（ $\propto$ 反 応率）を表す。この結果から，触媒濃度が $1 \%$ の場合は 酢酸のほうが鉣酸よりも $\mathrm{Cl}$ 濃度が高く反応率が高いこ と, 酢酸を用いた場合はその濃度が高いほど反応率が高 いことが分かった．したがって，触媒は $100 \%$ 酢酸を用 い，溶媒を兼ねることとした．

4・1・2 TCPH 濃度 触媒と溶媒とを兼ねた酢酸に $\mathrm{TCPH}$ を $6 \mathrm{wt} \%$ 添加した試薬濃度と $\mathrm{Cl}$ 濃度との関 係を Fig. 2 に示す。この結果から，TCPH 濃度が 2.5 $\mathrm{wt} \%$ で $\mathrm{Cl}$ 濃度が一定となり, 反応率が最大になること が分かった。

以上の結果から, 誘導体化試薬は触媒と溶媒とを兼ね た酢酸に TCPH を $2.5 \mathrm{wt} \%$ 添加することとし，以下の 実験ではすべてこの試薬組成を用いた.

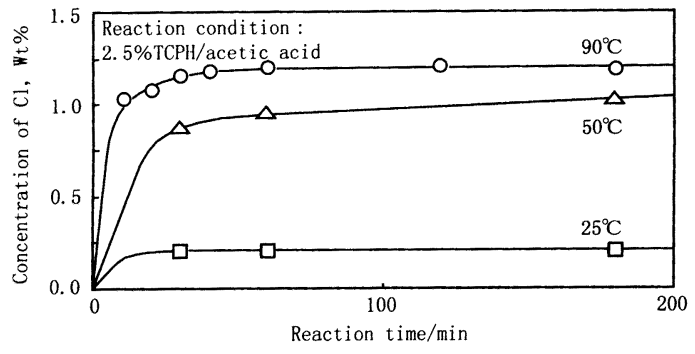

Fig. 3 Relation between the reaction time and the concentration of $\mathrm{Cl}$ obtained by EPMA after reaction

\section{$4 \cdot 2$ 反応時の温度, 時間と洗浄時間 \\ $4 \cdot 2 \cdot 1$ 反応温度と反応時間前項で求めた最適試} 薬組成を用いて, 反応温度, 反応時間を変化させたとき の $\mathrm{Cl}$ 濃度との関係を Fig. 3 に示す．実験は $120^{\circ} \mathrm{C}$ まで 行ったが, $100^{\circ} \mathrm{C}$ 以上で試料が変形してしまい, 測定不

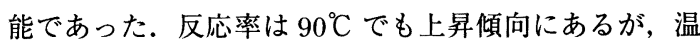
度に対する上昇率は低下しており，90 なりつつあることが分かった. また，反応温度が $90^{\circ} \mathrm{C}$ のときは $\mathrm{Cl}$ 濃度がほほ 30 分で一定となり, 反応率が 最大になることが分かった.

$\mathbf{4} \cdot \mathbf{2} \cdot 2$ 洗浄時間 反応後に試料中に残った未反応 の誘導体化試薬を除くために，酢酸で洗浄した．洗浄は $90^{\circ} \mathrm{C}$ と室温 $\left(25^{\circ} \mathrm{C}\right)$ で 30 分まで検討したが，温度に関 係なく 10 分程度で一定になることが分かったため, 室 温で 10 分間行うことにした。また，洗浄後の $\mathrm{Cl}$ 濃度 は洗浄前とさほど変わらなかったことから, 試料中に浸 透した誘導体化試薬はすべて反応し，洗浄前後の差分は 試料表面に吸着した反応試薬と考えられる.

以上の結果から, 反応温度は $90^{\circ} \mathrm{C}$, 反応時間は 30 分, 洗浄時間は 10 分, 洗浄温度は室温 $\left(25^{\circ} \mathrm{C}\right)$ とすること にし，以下の実験はすべてこの条件で行った。

\section{$4 \cdot 3$ 反応深さ, 反応率及び反応の選択性}

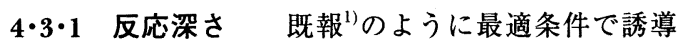
体化した反応面をミクロトームで傾斜切削した後，切削 面を EPMA により，フィルムを顕微 IR 法により線分析 することで反応深さを調べた．その結果を Fig. 4 に示 す，横軸に反応面からの深さを表し，左縦軸に EPMA で求めた $\mathrm{Cl}$ 濃度を, 右縦軸に顕微 IR で求めた 1720 $\mathrm{cm}^{-1}(v \mathrm{C}=\mathrm{O})$ の吸光度を表した。この結果から，反 応深さは $10 \mu \mathrm{m}$ 程度であり，高分子材料における EPMAの検出深さに達していることが確認された。ま 

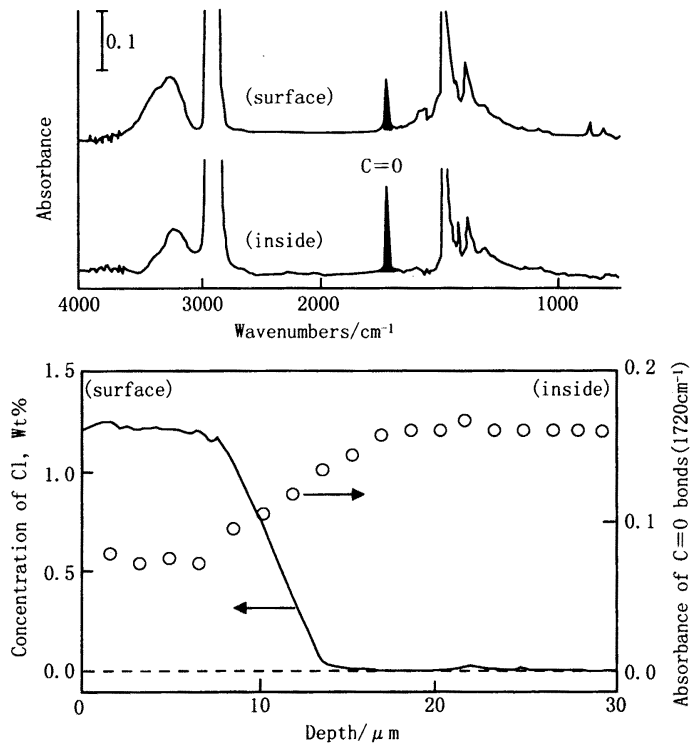

Fig. 4 IR spectra of derivatized E-CO polymer (upper) and depth profiles of $\mathrm{C}=\mathrm{O}$ bonds in derivatized E-CO polymer for the measurement of derivatization reaction depth (lower)

た，上図の IR スペクトルからは表面のカルボニル基の 吸光度が内部より減少しており, 確かに誘導体化が起こ っていることが確認できる.

$4 \cdot 3 \cdot 2$ 反応率 Fig. 4 上図で未反応部（内部）の 顕微 IR による吸光度が 0.18 であるのに対して，反応部 （表面）のそれは 0.09 であることから，反応率は $50 \%$ しかないことが分かる．これは，反応試薬の分子量が大 き過ぎたか, E-CO ポリマー中の C = O の半数が立体障 害を起こしているためと考えられる.

4・3・3 反応の選択性 本法によって官能基の分析 を行うに当たっては, 目的の官能基のみが誘導体化され て，ほかの官能基とは反応しないこと（反応の選択性） が重要である. $3 \cdot 1 \cdot 1$ 項に示す種々の官能基を持つ高分 子を同じ条件で反応させた結果，カルボニル基を持たな いポリマーにはほとんど反応せず，今回求めた誘導体化 条件で高い選択性が得られた. なお, 本法によるカルボ ニル基の検出限界は $S / N=2$ で $0.01 \%$ であり，顕微 IR 法のそれが $0.3 \%$ であるのに対して，30 倍の感度であ る.この濃度はポリエチレン中に生成するカルボニル基 量に換算すると, エチレンユニット 1 万個当たり 1 個 のカルボニル基量に相当する. また, 既報より ${ }^{1)}$ 高分子 材料の EPMA 分析における位置分解能は約 $3 \mu \mathrm{m}$ である ことから, 誘導体化後の試料を EPMA 分析した場合の

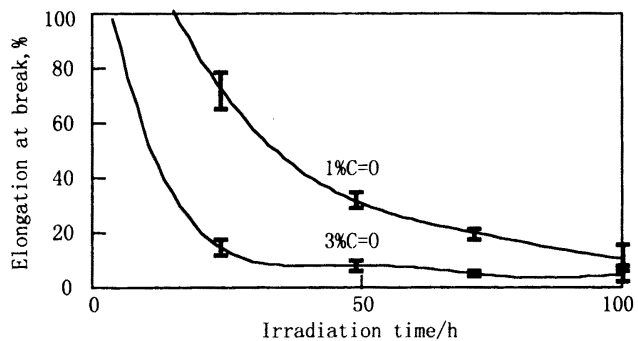

Fig. 5 Relation between the irradiation time and the elongation at break on E-CO copolymer films degraded by the xenon light

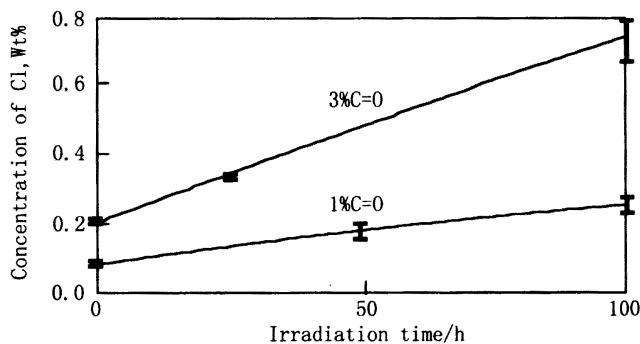

Fig. 6 Relation between the irradiation time and the concentration of $\mathrm{Cl}$ obtained by EPMA on E-CO copolymer films degraded by the xenon light

分解能も約 $3 \mu \mathrm{m}$ と考えられる.

$$
5 \text { 応用 }
$$

$5 \cdot 1$ 劣化 E-CO ポリマー中のカルボニル基の分布分析 光崩壊性の E-CO ポリマーは農業用フィルムに用いら れている.このポリマーはカルボニル基が感光基とな り, 約 $290 \mathrm{~nm}$ の光を吸収し Norrish I, II 型の光分解を 起こすことが知られている7) 9).ここでは, このポリマ 一（カルボニル基の濃度: $1 \% ， 3 \%$ )を試料として，キ セノン光源で劣化させた場合のカルボニル基の挙動を調 ベた.キセノン光源には島津製 Suntester XF-180 キセノ ンテスター 侊強度: $\left.11 \mathrm{~mW} / \mathrm{cm}^{2}(300 \sim 400 \mathrm{~nm})\right\}$ を 用いた. Fig. 5 に照射時間と破断伸びとの関係を，Fig. 6 に照射時間とフィルム表面のカルボニル基の濃度 $(\mathrm{Cl}$ 濃度）との関係を示す。これより, 初期のカルボニル基 の濃度が高いものほど破断伸びの低下が速く, 生成する カルボニル基の増加が大きいことが分かった. Fig. 7 に 初期と 100 時間照射後の E-CO ポリマー中のカルボニル 基の梁さ方向分布を示す. 表面と同様裏面でもカルボニ 


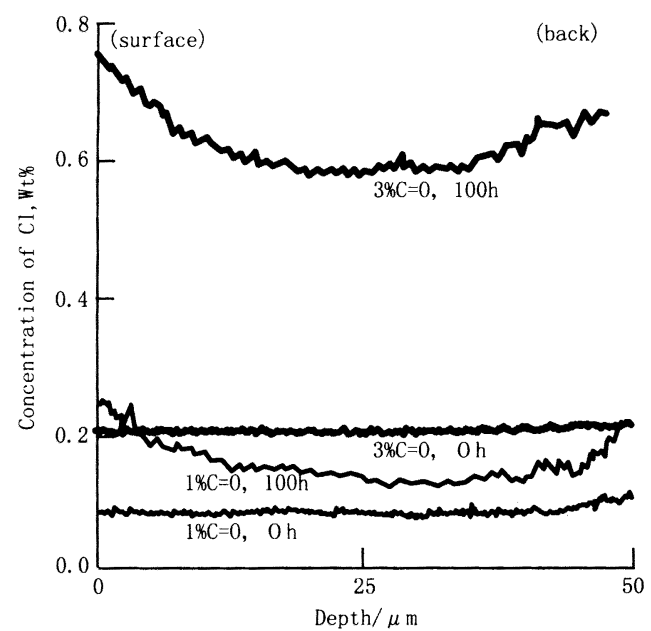

Fig. 7 Depth profiles of $\mathrm{C}=\mathrm{O}$ bonds in $\mathrm{E}-\mathrm{CO}$ copolymer films degraded by the xenon light

ル基の生成量が多く，通常の透明ポリマー材料の酸化劣 化の分布と同様の傾向であった.

このカルボニル基の増加は, Norrish I, II 型の光分解 で生じたラジカルや二重結合をきっかけとする光酸化あ るいは熱酸化によるものと推察される.

\section{$5 \cdot 2$ 劣化ポリエチレン中のカルボニル基の分布分析}

屋外ばく露したポリエチレン中のカルボニル基の深さ 方向分布を Fig. 8 に示す. また，比較のため同一試料 を顕微 IR で線分析し， EPMA 測定で Cl 濃度が最大とな った位置の赤外吸収スペクトルを Fig. 8 上段に示す. 誘導体化/EPMA 法で分布を測定した場合は，6，12， 24 か月とばく露期間が長くなるのに従い, カルボニル 基が増加していく様子, 表面から内部にカルボニル基の 生成が進行している様子が明確にとらえられている.こ れに対して，顕微 IRでは 6 か月ばく露した試料におい てはカルボニル基が最大である最表面の IR スペクトル にもかかわらず，カルボニル基などの酸化劣化生成物が 検出されておらず，本法の感度の高さが確認できた。 ま た，表面でのカルボニル基の分布は $5 \cdot 1$ 項に記したキ セノン光源による劣化形態と異なり, 最表面でのカルボ ニル基の減少が観察された.これは屋外ばく露で生成し た高極性の劣化生成物が雨で抽出されることによるもの と考えられる。

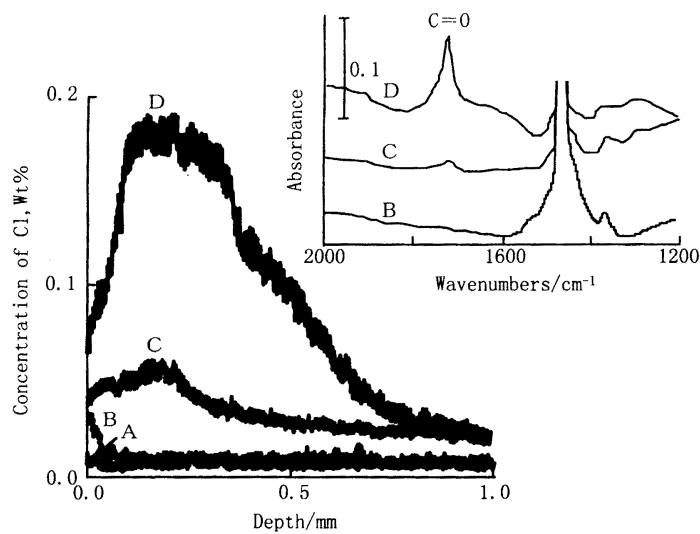

Fig. 8 Depth profiles of $\mathrm{C}=\mathrm{O}$ bonds in polyethylene degraded by outdoor-exposure (left) and IR spectra at peak top depth (right)

A: initial; B: 6 months; C: 12 months; D: 24 months

以上のように，2,4,6-トリクロロフェニルヒドラジン を誘導体化試薬とした誘導体化/EPMA 法によって，高 分子材料中のカルボニル基の分布が検出限界 $0.01 \%$ で 測定することが可能となった. 本法は，ポリエチレンな どポリオレフィンの酸化劣化状態の解析に有効であると 考えられる.

$\left(\begin{array}{l}1995 \text { 年 } 5 \text { 月, 第 } 56 \text { 回分析 } \\ \text { 化学討論会にて一部発表 }\end{array}\right)$

\section{文献}

1) 杉浦元保, 村瀬 篤, 光岡拓哉, 荒賀年美: 分 析化学 (Bunseki Kagaku), 45, 251 (1994).

2) 村瀬 篤, 光岡拓哉, 杉浦元保, 荒賀年美: 分 析化学 (Bunseki Kagaku), 46, 37 (1997).

3) D. Briggs, C. R. Kendall: Polymer, 20, 1053 (1979).

4) D. R. Burfield, K. S. Law: Polymer, 20, 620 (1979).

5) I. Sutherland, E. Sheng, D. M. Brewis: J. Mater. Chem., 4, 683 (1994).

6) T. Ohmichi, H. Tamaki, H. Kawasaki, S. Tatsuta: 富士写真フィルム研究報告, 29, 102 (1984).

7) 徳丸克己: “有機光化学反応論”, (1979), (東京化 学同人).

8) W. Schnabel: "Polymer Degradation", p. 112 (1981), (Hansen International, Munchen).

9) R. J. Statz, M. C. Dorris: Proc. SPI Symp. on Degrad. Plstics, Washington D.C., p. 51 (1987). 


\section{要旨}

高分子材料の劣化によって生じる微量なカルボニル基の分布を誘導体化/電子プローブ $\mathrm{X}$ 線マイクロ アナリシス (EPMA) によって高感度に分析するため, カルボニル基を選択的に誘導体化する新しい試 薬として，2,4,6-トリクロロフェニルヒドラジン（TCPH）を見いだした。この試薬を用い, 触媒, 試薬 濃度, 反応温度, 反応時間などの誘導体化条件の最適化を行った結果, $2.5 \% \mathrm{TCPH} /$ 酶酸溶液中に試料 を入れ， $90^{\circ} \mathrm{C}$ で 30 分反応させることにより, 最も高い反応率と反応の選択性が得られた. 酢酸は触媒 と溶媒とを兼ねた。これにより, 高分子材料中のカルボニル基の分布が検出限界 $0.01 \%$ で測定可能とな った. 本法を劣化させた高分子材料の深さ方向分析に適用し, ポリエチレンなどのポリオレフィンの酸 化劣化挙動の解析に有効であることを確認した. 